\title{
Mediterranean diet and telomere length in Nurses' Health Study: population based cohort study
}

\author{
(c) (1) ()
}

\author{
Marta Crous-Bou postdoctoral research fellow ${ }^{1}$ research fellow ${ }^{2}$, Teresa T Fung associate professor ${ }^{3}$ \\ adjunct associate professor ${ }^{4}$, Jennifer Prescott instructor in medicine ${ }^{1}$, Bettina Julin postdoctoral \\ research fellow ${ }^{1}$ research fellow ${ }^{2}$, Mengmeng Du postdoctoral research fellow ${ }^{1}$ research fellow ${ }^{5}$, \\ Qi Sun assistant professor ${ }^{14}$, Kathryn M Rexrode associate professor ${ }^{7}$, Frank B Hu professor ${ }^{124}$, \\ Immaculata De Vivo associate professor ${ }^{12}$
}

${ }^{1}$ Channing Division of Network Medicine, Department of Medicine, Brigham and Women's Hospital and Harvard Medical School, Boston, MA 02115, USA; ${ }^{2}$ Department of Epidemiology, Program in Genetic Epidemiology and Statistical Genetics, Harvard School of Public Health, Boston, MA 02115, USA; ${ }^{3}$ Department of Nutrition, Simmons College, Boston, MA 02115, USA; ${ }^{4}$ Department of Nutrition, Harvard School of Public Health, Boston; ${ }^{5}$ Public Health Sciences Division, Fred Hutchinson Cancer Research Center, Seattle, WA 98109, USA; ${ }^{6}$ School of Public Health, University of Washington, Seattle, WA 98195, USA; ${ }^{7}$ Division of Preventive Medicine, Department of Medicine, Brigham and Women's Hospital and Harvard Medical School, Boston

\begin{abstract}
Objective To examine whether adherence to the Mediterranean diet was associated with longer telomere length, a biomarker of aging.

Design Population based cohort study

Setting Nurses' Health Study, an ongoing prospective cohort study of 121700 nurses enrolled in 1976; in 1989-90 a subset of 32825 women provided blood samples.

Participants 4676 disease-free women from nested case-control studies within the Nurses' Health Study with telomere length measured who also completed food frequency questionnaires.
\end{abstract}

Main outcome measure Association between relative telomere lengths in peripheral blood leukocytes measured by quantitative real time polymerase chain reaction and Alternate Mediterranean Diet score calculated from self reported dietary data.

Results Greater adherence to the Mediterranean diet was associated with longer telomeres after adjustment for potential confounders. Least squares mean telomere length z scores were -0.038 (SE 0.035) for the lowest Mediterranean diet score groups and $0.072(0.030)$ for the highest group ( $P$ for trend=0.004).

Conclusion In this large study, greater adherence to the Mediterranean diet was associated with longer telomeres. These results further support the benefits of adherence to the Mediterranean diet for promoting health and longevity.

\section{Introduction}

The traditional Mediterranean diet is characterized by a high intake of vegetables, fruits, nuts, legumes, and grains (mainly unrefined); a high intake of olive oil but a low intake of saturated lipids; a moderately high intake of fish; a low intake of dairy products, meat, and poultry; and a regular but moderate intake of alcohol (specifically wine with meals). ${ }^{1}$ Observational studies and intervention trials have consistently shown the health benefits of a high degree of adherence to the Mediterranean diet, including reduction of overall mortality ${ }^{2-4}$; reduced incidence of chronic diseases, especially major cardiovascular diseases $^{5}$; and increased likelihood of healthy aging. ${ }^{6}$

Telomeres are repetitive DNA sequences at the ends of eukaryotic chromosomes that undergo attrition each time a somatic cell divides. ${ }^{7}$ Telomeres prevent the loss of genomic DNA at the ends of linear chromosomes and in turn protect their physical integrity. ${ }^{89}$ Telomere attrition has been shown to be accelerated by oxidative stress and inflammation. ${ }^{10}{ }^{11}$ Telomere length is considered to be a biomarker of aging; shorter telomeres are associated with a decreased life expectancy and increased rates of developing age related chronic diseases. ${ }^{12-14}$ Telomere length decreases with age and varies considerably among individuals. ${ }^{15}$ Studies suggest that telomere attrition is modifiable, as substantial variability exists in the rate of telomere shortening that is independent of chronological age..$^{16-18}$ Therefore, variability of telomere length may be partially explained by lifestyle practices, including dietary patterns. ${ }^{19}$ As accelerated telomere attrition may underlie many chronic diseases, identifying modifiable factors that affect telomere dynamics is important. 
Given that fruits, vegetables, and nuts, key components of the Mediterranean diet, have well known antioxidant and anti-inflammatory effects, and that telomere length is affected by both of these processes, we hypothesized that greater adherence to the Mediterranean diet would be associated with longer telomere length. Therefore, the main objective of this study was to examine the association between greater adherence to the Mediterranean diet and leukocyte telomere length in US women within the Nurses' Health Study cohort. For comparison, we also evaluated the association between other existing dietary patters (prudent pattern, Western pattern, and Alternative Healthy Eating Index) and leukocyte telomere length.

\section{Methods}

\section{Study population}

The Nurses' Health Study is a prospective cohort study of 121 700 female registered nurses in 11 US states, aged 30-55 years at enrollment. The study was established in 1976; since then, participants have completed biennial questionnaires to update information on demographic characteristics, lifestyle factors, and newly diagnosed diseases. ${ }^{20}{ }^{21}$ Between 1989 and 199032 825 cohort participants provided blood samples. Details of the blood collection and archival methods have been described previously. $^{22}$

Multiple nested case-control studies have been conducted within the Nurses' Health Study blood sub-cohort to investigate the association between leukocyte telomere length and cancer, cardiovascular disease, and cognitive function, among others. ${ }^{23-28}$ The analysis reported here included data on 4676 women selected as healthy controls (free of major chronic diseases, including cancer and cardiovascular disease) from nested case-control studies, with previously measured leukocyte telomere length and completed food frequency questionnaires at the time of blood draw.

\section{Dietary assessment}

In 1980 participants completed a 61 item semi-quantitative food frequency questionnaire to assess their diet in the previous year. In 1984, 1986, and every four years thereafter, an expanded food frequency questionnaires containing 116-130 food items was sent to the nurses to update their dietary information. Participants were asked about the frequency of consumption of each food item of a pre-specified standard portion size in the previous year. The validity of these questionnaires has been previously described. ${ }^{29} \mathrm{We}$ calculated all dietary patterns and diet quality scores from self reported dietary data on the 1990 food frequency questionnaire, the closest to the blood draw (1989-90).

Trichopoulou adapted the Alternate Mediterranean Diet score from the Mediterranean Diet Score to assess adherence to the traditional Mediterranean diet. ${ }^{2}$ The Alternate Mediterranean Diet score includes the following nine components: vegetables (excluding potatoes), fruits, nuts, whole grains, legumes, fish, monounsaturated:saturated fatty acid ratio, red and processed meats, and moderate alcohol intake. The possible score range is 0-9, with a higher score representing a closer resemblance to the Mediterranean diet. We dichotomized each of the nine dietary components at the median. We gave participants with intake above the median 1 point each for vegetables, fruits, nuts, whole grains, legumes, fish, and monounsaturated:saturated fatty acid ratio; we scored intake equal to or below the median as 0 points for each component. We scored red and processed meat consumption below the median as 1 point, with 0 points for intake equal to or above the median. Participants received
1 point for alcohol intake between 5 and $15 \mathrm{~g} /$ day; otherwise, they got 0 points. Details of the Alternate Mediterranean Diet scoring system are described elsewhere. ${ }^{3}$

We used principal component analysis of the food frequency questionnaires to identify prudent and Western dietary patterns. ${ }^{30}{ }^{31}$ The prudent dietary pattern is characterized by high intakes of fruits, vegetables, legumes, fish and other seafood, poultry, and whole grains; the Western dietary pattern includes high intakes of red and processed meats, butter, high fat dairy products, eggs, sweets and desserts, French fries, and refined grains. Details of the reproducibility and validity of dietary patterns assessed with a food frequency questionnaire have been previously described. ${ }^{30} 31$

The Alternative Healthy Eating Index measures adherence to a dietary pattern based on foods and nutrients most predictive of risk for chronic disease in the literature. ${ }^{32}$ The Alternative Healthy Eating Index ranges from 0 to 110 points. Each of the 11 components of the score (vegetables, fruits, whole grains, sugar sweetened drinks, nuts and legumes, red and processed meat, trans fat, long chain (n-3) fats, polyunsaturated fatty acids, sodium, and alcohol) has a minimum score of 0 (worst) and a maximum score of 10 (best), according to component specific criteria reflecting either the current dietary guidelines or associations reported in the literature. Details of component selection and Alternative Healthy Eating Index calculation have been previously described. ${ }^{32}$

\section{Covariate assessment}

In addition to age at blood draw, we collected information on factors potentially associated with Mediterranean diet and telomere length. Using the biennial questionnaires completed proximal to blood collection and a supplemental questionnaire administered at blood collection, we assessed various anthropometric, reproductive, and lifestyle factors, as well as factors that have been related to telomere length in the Nurses' Health Study elsewhere: body mass index $\left(\mathrm{kg} / \mathrm{m}^{2}\right)$, cigarette smoking (pack years), ${ }^{33-35}$ physical activity (total metabolic equivalent hours of activity per week). ${ }^{16} \mathrm{We}$ calculated dietary factors, including energy intake (total calories), from the 1990 food frequency questionnaire.

\section{Telomere length measurement}

Genomic DNA was extracted from peripheral blood leukocytes using the QIAmp 96-spin blood protocol (Qiagen, Chatsworth, CA, USA). Pico-Green quantification of genomic DNA was performed using a Molecular Devices 96 well spectrophotometer (Sunnyvale, CA, USA).

Relative telomere length was determined using a modified, high throughput version of the quantitative real time polymerase chain reaction based telomere assay. ${ }^{36}{ }^{37}$ The quantitative real time polymerase chain reaction telomere assay was run on the Applied Biosystems 7900HT Sequence Detection System (Foster City, CA, USA). Laboratory personnel were blinded to participants' characteristics, and all assays were processed in triplicate by the same technician and under identical conditions.

The average relative leukocyte telomere length was calculated as the ratio of telomere repeat copy number to a single gene (36B4) copy number. Leukocyte telomere length is reported as the exponentiated ratio of telomere repeat copy number to a single gene copy number corrected for a reference sample. In all nested case-control studies, the telomere and single gene assay coefficients of variation for triplicates were less than $4 \%$. Coefficients of variation for the exponential ratio of telomere repeat copy number to a single gene copy number were under 
$18 \%$. In the Nurses' Health Study, the three year and 10 year interclass correlations for reliability were determined to be 0.80 and 0.60 . Although this assay provides a relative measurement of telomere length, ratios of telomere repeat copy number to a single gene copy number highly correlate with absolute telomere lengths determined by Southern blot $(r=0.677 ; \mathrm{P}<0.001){ }^{36}$

Telomere length was assayed in various batches corresponding to each study. To minimize the impact of potential batch effect on leukocyte telomere length measurements across different studies, we calculated $\mathrm{z}$ scores of log transformed leukocyte telomere length by standardizing the leukocyte telomere length in comparison with the mean within each individual study. ${ }^{19} 38$

\section{Statistical analysis}

We used Spearman's partial rank correlation coefficients to examine age adjusted associations between characteristics of the study population, quarters of leukocyte telomere length, and Alternate Mediterranean Diet score groups.

We used multivariable linear regression models to determine the cross sectional association between leukocyte telomere length and adherence to the Mediterranean diet. We calculated multivariable adjusted least squares mean leukocyte telomere length $\mathrm{z}$ scores (and their corresponding 95\% confidence intervals) across all dietary patterns score groups by using generalized linear models. Firstly, only age at blood draw was included in the models. Models were then additionally adjusted for other potential confounders (body mass index, smoking, physical activity, energy intake, and batch). Finally, other variables were included as potential covariates (for example, postmenopausal hormone therapy, history of hypertension, and socioeconomic status), but these were removed from the final models as estimates remained the same. All $\mathrm{P}$ values are two sided, and an $\alpha$ level of 0.05 was used. We used SAS version 9.2 for all statistical analyses. Reported STROBE guidelines have been the basis for reporting our results. ${ }^{39}$

\section{Results}

Table $1 \Downarrow$ shows the main age standardized characteristics of the study population by quarters of telomere length. The mean age of the participants was 59 (SD 6.6) years, and the exact age range of the participants included in our study was $42-70$ years. As expected, a statistically significant inverse correlation existed between age at blood draw and telomere length: younger women had longer telomeres $(\mathrm{P}<0.001)$. Moreover, women with shorter telomere length smoked slightly more $(\mathrm{P}=0.02)$. Distributions of main lifestyle factors between the study participants $(n=4676)$, in comparison with the rest of the Nurses' Health Study blood sub-cohort $(n=32825)$ after age standardization, were largely similar (results not shown).

Table $2 \Downarrow$ shows the baseline characteristics of the study participants across Alternate Mediterranean Diet score groups. The highest score group (score $\geq 6$ ) represents the closest resemblance to the Mediterranean diet. Compared with women in the lowest score group (score $\leq 2$ ), those in the highest score group were older at blood collection $(\mathrm{P}<0.001)$, had slightly lower body mass index $(\mathrm{P}=0.01)$, smoked less $(\mathrm{P}<0.001)$, had higher intake of total energy $(\mathrm{P}<0.001)$, and were more physically active $(\mathrm{P}<0.001)$. As expected, women with the highest Alternate Mediterranean Diet score also had higher intakes of vegetables, fruits, grains, fish, legumes, nuts, and total fat, as well as lower meat intake.

Table $3 \Downarrow$ shows the association between adherence to a Mediterranean diet and telomere length. Higher Alternate
Mediterranean Diet scores were associated with higher age adjusted mean leukocyte telomere length $\mathrm{z}$ scores $(\mathrm{P}$ for trend $=0.02$ ). The association remained statistically significant after inclusion of body mass index, pack years of smoking, physical activity, and total caloric intake in the models; the multivariable adjusted least squares mean leukocyte telomere length $\mathrm{z}$ score across Alternate Mediterranean Diet groups $(\leq 2$, $3,4,5, \geq 6$ ) was $-0.038,-0.049,-0.010,0.039$, and 0.072 (P for trend $=0.004$ ) (table $3 \Downarrow$ ). Additional adjustment for postmenopausal hormone therapy, age at menopause, history of hypertension, socioeconomic status, and case-control study set (batch), did not change the estimates (data not shown).

We also evaluated the association between leukocyte telomere length $\mathrm{z}$ score and each component in the Alternate Mediterranean Diet score (table $4 \Downarrow$ ). None of the individual components was significantly associated with telomere length, even after adjustment for multiple confounders (age, body mass index, pack years of smoking, physical activity, total caloric intake, and mutual adjustment for other components of the Alternate Mediterranean Diet score) (table $4 \Downarrow$ ).

The figure $\downarrow$ shows the association between other dietary patterns and leukocyte telomere length. Similar to the Alternate Mediterranean Diet score, a higher Alternative Healthy Eating Index (that is, healthy eating) showed a weak positive association with longer telomere length $(\mathrm{P}=0.02)$, but we found no statistically significant associations for the prudent $(\mathrm{P}=0.09)$ or Western dietary patterns $(\mathrm{P}=0.32)($ fig $\downarrow)$. Additional adjustment for body mass index, pack years of smoking, physical activity, and total caloric intake did not alter the estimates.

\section{Discussion}

In this large cross sectional study of 4676 healthy middle aged and older women from the well characterized Nurses' Health Study, greater adherence to the Mediterranean diet was significantly associated with longer leukocyte telomere length. Notably, whereas higher Alternate Mediterranean Diet score was significantly associated with longer leukocyte telomere length, none of the individual components showed an association with leukocyte telomere length, emphasizing the importance of examining the relation between dietary patterns, in addition to separate dietary factors, and health. This suggests that the association may be a consequence of the global effect of the overall Mediterranean diet. The Alternative Healthy Eating Index was also associated with longer telomere length; however, the strongest association was observed among women with greater adherence to the Mediterranean diet.

The difference in telomere length for each one point change in the Alternate Mediterranean Diet score corresponded on average to 1.5 years of aging. A three point change in the Alternate Mediterranean Diet score would correspond to on average 4.5 years of aging, which is comparable to the difference observed when comparing smokers with non-smokers (4.6 years), ${ }^{35}$ highly active women with less active women (4.4 years),${ }^{16}$ and women with high phobic anxiety scores with women with low phobic anxiety (6 years). ${ }^{17}$

\section{Comparison with previous literature}

To our knowledge, this is the largest population based study specifically looking at the association between adherence to the Mediterranean diet and telomere length in healthy, middle aged women. Our results are consistent with previously published literature on the benefits of a healthy lifestyle, particularly diet, and telomere length. 
To date, only one study has assessed the association between telomere length, telomerase activity, and different adherence to a Mediterranean diet. ${ }^{40}$ The 217 older people in this study had a mean age of 77 , and the upper age limit for reliable assessment of telomere length is $75 .{ }^{41}$ Using an older age group is considered inappropriate because of "survivor" bias ${ }^{42} 43$ : people who live longer tend to be more resilient to chronic disease and possess longer telomeres. The authors may be capturing survivor bias rather than an association between telomere length and adherence to a Mediterranean diet.

García-Calzón et al studied the association between telomere length and changes in adiposity indices after a five year intervention study with a Mediterranean diet, ${ }^{44}$ in the context of the PREDIMED-NAVARRA trial. ${ }^{5}$ In this particular study, the outcome was obesity, and the association between telomere length and the whole Mediterranean diet was not specifically examined.

Only two studies have examined the relation between a healthy lifestyle pattern and leukocyte telomere length. ${ }^{19}{ }^{34}$ Mirabello et al observed a positive association between a healthy lifestyle (defined by low risk factors including low or no smoking, higher intakes of fruits and vegetables, lower body mass index, and greater physical activity) and leukocyte telomere length in men. ${ }^{34}$ Similarly, Sun et al reported that a healthy lifestyle pattern (defined by five components: smoking, physical activity, adiposity, alcohol use, and Alternative Healthy Eating Index) was associated with longer leukocyte telomere length in women. $^{19}$

One of the first studies to show a strong relation between physical fitness and telomere length in a large sample of patients with existing coronary heart disease was conducted by Krauss et al. ${ }^{45}$ They found that poor physical fitness was associated with shorter leukocyte telomere length in patients with coronary heart disease. Du et al reported, in the Nurses' Health Study, that physical activity (even moderate amounts of activity) was associated with longer telomeres. ${ }^{16}$ Moreover, Ornish et al recently published an intervention trial on the effect of comprehensive lifestyle changes (diet, activity, stress management, and social support) on telomerase activity and telomere length in men with low risk prostate cancer. ${ }^{46}$ Results from this pilot study showed that a comprehensive lifestyle intervention was associated with increases in relative telomere length after five years of follow-up, compared with controls.

Studies on the association between specific dietary factors and telomere length have yielded inconsistent results. ${ }^{34}{ }^{47-50}$ Cassidy et al, for instance, reported a positive association between leukocyte telomere length and dietary fiber intake but an inverse association between total fat intake (particularly, polyunsaturated fatty acids) and leukocyte telomere length. No significant associations were observed for intakes of vitamin D or fruits and vegetables. ${ }^{50}$ These findings support the importance of examining an overall lifestyle dietary pattern, rather than individual food components.

The Mediterranean diet score has been used to evaluate the association between the Mediterranean diet and overall mortality, as well as Alzheimer's disease, diabetes mellitus, coronary heart disease, and cancer overall. ${ }^{21-55}$ Trichopoulou A et al evaluated the contribution of the nine widely accepted components, which are used to build the Mediterranean diet score, and reported an inverse association of this diet with all cause mortality in a population based cohort in Greece. ${ }^{56}$ More interestingly, they found additive associations among components. The authors report that one of the advantages of using a Mediterranean diet score rather than focusing on the food components is the generation of fairly consistent results with respect to health benefits, whereas studies focusing on the components or food groups are often contradictory. As summarized by Trichopoulou et al ${ }^{56}$ chance, non-differential misclassification, and residual confounding may have more important consequences when individual food items are evaluated rather than a multi-component, unidimensional score. The benefits on health and aging from a greater adherence to the Mediterranean diet have been largely described. Adherence to the Mediterranean diet has been linked to lower all cause mortality, reduced incidence of major cardiovascular diseases and other chronic diseases, and greater health and wellbeing in people surviving to older ages. ${ }^{2-6}$

\section{Possible biologic mechanisms}

Oxidative stress and inflammation have been reported to accelerate telomere attrition. ${ }^{10}{ }^{1157}$ Moreover, given human telomere composition, these DNA regions are more sensitive to damage by oxidation. ${ }^{58}{ }^{59}$ In contrast, high antioxidative capacity slows telomere shortening. ${ }^{58}{ }^{60-62}$ The established protective effects of the Mediterranean diet on oxidative stress and chronic inflammation may explain the favorable influence of the Mediterranean diet on telomere length, pointing to a potential biologic mechanism behind the well known anti-aging effects of the Mediterranean diet.

The lack of an association with individual components is not surprising. Studies have proposed a possible synergy among the nutrient rich foods included in the Mediterranean diet that fosters favorable changes in intermediate pathways of cardiometabolic risk, such as insulin sensitivity and resistance to oxidation and inflammation, ${ }^{563}$ supporting the role of the Mediterranean diet as a whole.

\section{Strengths and limitations of study}

The strengths of our study include the large and well characterized study population, detailed assessment of dietary habits as well as other sociodemographic and lifestyle characteristics, and validated food frequency questionnaires and dietary scores. However, potential limitations should be considered. The cross sectional design precludes us from establishing a temporal association between dietary habits and telomere length. Leukocyte telomere length was assessed using a single measure, preventing the estimation of associations between Mediterranean diet and telomere attrition rate; assessing this requires a prospective study with repeated assessments of leukocyte telomere length. Although all analyses were adjusted for multiple covariates, unmeasured or residual confounding could still be present. Validation of self reported variables potentially associated with telomere length, such as self reported diabetes, hypertension, and obesity, has been done previously. ${ }^{64-66}$ Finally, the Nurses' Health Study population predominantly includes women of European ancestry, and telomere dynamics may differ among other ethnicities ${ }^{67-69}$; therefore, results may not be generalized. However, the homogeneity among Nurses' Health Study participants strengthens the internal validity of these findings by maximizing the quality of reported data.

\section{Conclusion}

In summary, greater adherence to the Mediterranean diet was significantly associated with longer leukocyte telomere length, a marker of biological aging. Our results further support the health benefits of adherence to the Mediterranean diet. 


\section{What is already known on this topic}

The Mediterranean diet has been consistently linked with health benefits, including reduced mortality and reduced risk of chronic diseases No study has examined whether adherence to the Mediterranean diet is associated with longer telomere length, a biomarker of aging

\section{What this study adds}

Greater adherence to the Mediterranean diet was associated with longer telomeres

Telomere length variability may be partially explained by lifestyle practices; as accelerated telomere attrition may underlie many chronic diseases, identifying modifiable factors that affect telomere dynamics is important

The results further support the benefits of adherence to the Mediterranean diet for promoting health and longevity

We thank the participants and staff of the Nurses' Health Study for their valuable contributions, as well as the following state cancer registries for their help: AL, AZ, AR, CA, CO, CT, DE, FL, GA, ID, IL, IN, IA, KY, LA, ME, MD, MA, MI, NE, NH, NJ, NY, NC, ND, OH, OK, OR, PA, RI, SC, TN, TX, VA, WA, and WY. We also thank Channing Division of Network Medicine, Department of Medicine, Brigham and Women's Hospital and Harvard Medical School. Finally, we acknowledge Patrice Soule and Esther Orr for their laboratory assistance, and Meir J Stampfer, Walter Willet, and JoAnn Manson for their insightful comments on the manuscript.

Contributors: MC-B was the lead author, and IDV was the senior author; both proposed the hypothesis and planned the analysis. MC-B analyzed the data and wrote the first draft of the manuscript. MC-B and IDV contributed to all aspects of the study design, data collection, data analysis and interpretation, and the writing of the article. IDV was the expert on telomere length. TTF and FBH created and validated the dietary scores and contributed to data collection, data interpretation, and the writing of the article. BJ and QS supervised the dietary analysis and data interpretation and contributed to the writing of the article. JP contributed to telomere data cleaning and collection. JP and MD supervised telomere analysis and contributed to data interpretation and the writing of the article. KMR contributed to data collection, data interpretation, and the writing of the article. All authors read and approved the final version of the manuscript. IDV is the guarantor.

Funding: The Nurses' Health Study is supported by the National Cancer Institute, National Institutes of Health (1R01 CA134958, 2R01 CA082838, P01 CA087969, R01 CA49449, CA065725, CA132190, CA139586, CA140790, CA133914, CA132175, CA163451, HL088521, HL60712, U54 CA155626, R01 AR059073, HL34594). MC-B is also supported by a Sara Borrell postdoctoral fellowship from the Spanish Ministry of Health, Carlos III Health Institute. MD is supported by grant R25 CA94880 from the National Cancer Institute. QS is supported by an NHLBI sponsored career development award (R00HL098459). The funders had no role in study design, data collection and analysis, decision to publish, or preparation of the manuscript.

Competing interests: All authors have completed the ICMJE uniform disclosure form at www.icmje.org/coi_disclosure.pdf and declare: no support from any organization for the submitted work other than those described above; no financial relationships with any organizations that might have an interest in the submitted work in the previous three years; no other relationships or activities that could appear to have influenced the submitted work.

Ethical approval: The study protocol was approved by the Human Research Committee at the Brigham and Women's Hospital (Boston, $M A)$, with written informed consent from all participants.

Transparency: The lead author (the manuscript's guarantor) affirms that the manuscript is an honest, accurate, and transparent account of the study being reported; that no important aspects of the study have been omitted; and that any discrepancies from the study as planned (and, if relevant, registered) have been explained.

Data sharing: A detailed plan for common data sharing procedures to be used in the Nurses' Health Study has been reviewed by Nurses' Health Study external advisory committee, which endorses the use of a data enclave approach to data sharing. Along with a general description of the cohort, the policies and guidelines for access to biospecimens and questionnaire data are published on the Nurses' Health Study website (www.channing.harvard.edu/nhs/) for outside investigators interested in accessing the resources of the study.

Willett WC, Sacks F, Trichopoulou A, Drescher G, Ferro-Luzzi A, Helsing E, et al. Mediterranean diet pyramid: a cultural model for healthy eating. Am J Clin Nutr 1995;61(6 suppl):1402-6S.

2 Trichopoulou A, Costacou T, Bamia C, Trichopoulos D. Adherence to a Mediterranean diet and survival in a Greek population. N Engl J Med 2003;348:2599-608.

3 Fung TT, Rexrode KM, Mantzoros CS, Manson JE, Willett WC, Hu FB. Mediterranean diet and incidence of and mortality from coronary heart disease and stroke in women. Circulation 2009;119:1093-100.

4 Lopez-Garcia E, Rodriguez-Artalejo F, Li TY, Fung TT, Li S, Willett WC, et al. The Mediterranean-style dietary pattern and mortality among men and women with cardiovascular disease. Am J Clin Nutr 2014;99:172-80.

5 Estruch R, Ros E, Salas-Salvado J, Covas MI, Corella D, Aros F, et al. Primary prevention of cardiovascular disease with a Mediterranean diet. N Engl J Med 2013;368:1279-90.

6 Samieri C, Sun Q, Townsend MK, Chiuve SE, Okereke OI, Willett WC, et al. The association between dietary patterns at midlife and health in aging: an observational study. Ann Intern Med 2013;159:584-91.

7 Blackburn EH. Structure and function of telomeres. Nature 1991;350:569-73.

8 D'Adda di Fagagna F, Reaper PM, Clay-Farrace L, Fiegler H, Carr P, Von Zglinicki T, et al. A DNA damage checkpoint response in telomere-initiated senescence. Nature 2003;426:194-8.

9 Abbott A. Chromosome protection scoops Nobel. Nature 2009;461:706-7.

10 Von Zglinicki T. Oxidative stress shortens telomeres. Trends Biochem Sci 2002;27:339-44.

11 Aviv A. Telomeres and human aging: facts and fibs. Sci Aging Knowledge Environ 2004;2004(51):pe43.

12 Blasco MA. Telomeres and human disease: ageing, cancer and beyond. Nat Rev Genet 2005;6:611-22.

13 Calado RT, Young NS. Telomere diseases. N Engl J Med 2009;361:2353-65.

14 Haycock PC, Heydon EE, Kaptoge S, Butterworth AS, Thompson A, Willeit P. Leucocyte telomere length and risk of cardiovascular disease: systematic review and meta-analysis. BMJ 2014;349:g4227.

15 Aviv A, Chen W, Gardner JP, Kimura M, Brimacombe M, Cao X, et al. Leukocyte telomere dynamics: longitudinal findings among young adults in the Bogalusa Heart Study. Am J Epidemiol 2009;169:323-9.

16 Du M, Prescott J, Kraft P, Han J, Giovannucci E, Hankinson SE, et al. Physical activity, sedentary behavior, and leukocyte telomere length in women. Am J Epidemiol 2012;175:414-22.

17 Okereke OI, Prescott J, Wong JY, Han J, Rexrode KM, De Vivo I. High phobic anxiety is related to lower leukocyte telomere length in women. PLoS One 2012;7:e40516.

18 Prescott J, Du M, Wong JY, Han J, De Vivo I. Paternal age at birth is associated with offspring leukocyte telomere length in the nurses' health study. Hum Reprod 2012;27:3622-31.

19 Sun Q, Shi L, Prescott J, Chiuve SE, Hu FB, De Vivo I, et al. Healthy lifestyle and leukocyte telomere length in U.S. women. PLoS One 2012;7:e38374.

20 Colditz GA. The nurses' health study: a cohort of US women followed since 1976. J Am Med Womens Assoc 1995;50:40-4.

21 Colditz GA, Martin P, Stampfer MJ, Willett WC, Sampson L, Rosner B, et al. Validation of questionnaire information on risk factors and disease outcomes in a prospective cohort study of women. Am J Epidemiol 1986;123:894-900.

22 Hankinson SE, Manson JE, Spiegelman D, Willett WC, Longcope C, Speizer FE. Reproducibility of plasma hormone levels in postmenopausal women over a 2-3-year period. Cancer Epidemiol Biomarkers Prev 1995;4:649-54.

23 Chiuve SE, Rexrode KM, Spiegelman D, Logroscino G, Manson JE, Rimm EB. Primary prevention of stroke by healthy lifestyle. Circulation 2008;118:947-54.

24 Page JH, Ma J, Rexrode KM, Rifai N, Manson JE, Hankinson SE. Plasma dehydroepiandrosterone and risk of myocardial infarction in women. Clin Chem 2008;54:1190-6.

25 De Vivo I, Prescott J, Wong JY, Kraft P, Hankinson SE, Hunter DJ. A prospective study of relative telomere length and postmenopausal breast cancer risk. Cancer Epidemiol Biomarkers Prev 2009;18:1152-6.

26 Han J, Qureshi AA, Prescott J, Guo Q, Ye L, Hunter DJ, et al. A prospective study of telomere length and the risk of skin cancer. $J$ Invest Dermatol 2009;129:415-21.

27 Prescott J, McGrath M, Lee IM, Buring JE, De Vivo I. Telomere length and genetic analyses in population-based studies of endometrial cancer risk. Cancer 2010;116:4275-82.

28 Devore EE, Prescott J, De Vivo I, Grodstein F. Relative telomere length and cognitive decline in the Nurses' Health Study. Neurosci Lett 2011;492:15-8.

29 Salvini S, Hunter DJ, Sampson L, Stampfer MJ, Colditz GA, Rosner B, et al. Food-based validation of a dietary questionnaire: the effects of week-to-week variation in food consumption. Int J Epidemiol 1989;18:858-67. 
30 Hu FB, Rimm E, Smith-Warner SA, Feskanich D, Stampfer MJ, Ascherio A, et al Reproducibility and validity of dietary patterns assessed with a food-frequency questionnaire. Am J Clin Nutr 1999;69:243-9.

31 Hu FB, Rimm EB, Stampfer MJ, Ascherio A, Spiegelman D, Willett WC. Prospective study of major dietary patterns and risk of coronary heart disease in men. Am J Clin Nutr 2000;72:912-21.

32 Chiuve SE, Fung TT, Rimm EB, Hu FB, McCullough ML, Wang M, et al. Alternative dietary indices both strongly predict risk of chronic disease. $J$ Nutr 2012:142:1009-18.

33 McGrath M, Wong JY, Michaud D, Hunter DJ, De Vivo I. Telomere length, cigarette smoking, and bladder cancer risk in men and women. Cancer Epidemiol Biomarkers Prev 2007;16:815-9.

34 Mirabello L, Huang WY, Wong JY, Chatterjee N, Reding D, Crawford ED, et al. The association between leukocyte telomere length and cigarette smoking, dietary and physical variables, and risk of prostate cancer. Aging Cell 2009:8:405-13.

35 Valdes AM, Andrew T, Gardner JP, Kimura M, Oelsner E, Cherkas LF, et al. Obesity, cigarette smoking, and telomere length in women. Lancet 2005;366:662-4.

36 Cawthon RM. Telomere measurement by quantitative PCR. Nucleic Acids Res 2002;30(10):e47.

37 Wang H, Chen H, Gao X, McGrath M, Deer D, De Vivo I, et al. Telomere length and risk of Parkinson's disease. Mov Disord 2008;23:302-5.

38 Liang G, Schernhammer E, Qi L, Gao X, De Vivo I, Han J. Associations between rotating night shifts, sleep duration, and telomere length in women. PLoS One 2011;6:e23462.

39 Von Elm E, Altman DG, Egger M, Pocock SJ, Gotzsche PC, Vandenbroucke JP. Strengthening the Reporting of Observational Studies in Epidemiology (STROBE) statement: guidelines for reporting observational studies. BMJ 2007;335:806-8.

40 Boccardi V, Esposito A, Rizzo MR, Marfella R, Barbieri M, Paolisso G. Mediterranean diet, telomere maintenance and health status among elderly. PLOS One 2013;8:e62781.

41 Martin-Ruiz CM, Gussekloo J, van Heemst D, von Zglinicki T, Westendorp RG. Telomere length in white blood cells is not associated with morbidity or mortality in the oldest old: a population-based study. Aging Cell 2005;4:287-90.

42 Bischoff C, Petersen HC, Graakjaer J, Andersen-Ranberg K, Vaupel JW, Bohr VA, et al. No association between telomere length and survival among the elderly and oldest old. Epidemiology 2006;17:190-4

43 Cawthon RM, Smith KR, O'Brien E, Sivatchenko A, Kerber RA. Association between telomere length in blood and mortality in people aged 60 years or older. Lancet 2003;361:393-5.

44 Garcia-Calzon S, Gea A, Razquin C, Corella D, Lamuela-Raventos RM, Martinez JA, et al. Longitudinal association of telomere length and obesity indices in an intervention study with a Mediterranean diet: the PREDIMED-NAVARRA trial. Int $J$ Obes (Lond) 2014:38:177-82.

45 Krauss J, Farzaneh-Far R, Puterman E, Na B, Lin J, Epel E, et al. Physical fitness and telomere length in patients with coronary heart disease: findings from the Heart and Sou Study. PLoS One 2011;6:e26983.

46 Ornish D, Lin J, Chan JM, Epel E, Kemp C, Weidner G, et al. Effect of comprehensive lifestyle changes on telomerase activity and telomere length in men with biopsy-proven low-risk prostate cancer: 5-year follow-up of a descriptive pilot study. Lancet Oncol 2013;14:1112-20

47 Bekaert S, De Meyer T, Rietzschel ER, De Buyzere ML, De Bacquer D, Langlois M, et al. Telomere length and cardiovascular risk factors in a middle-aged population free of overt cardiovascular disease. Aging Cell 2007;6:639-47.

48 Xu Q, Parks CG, DeRoo LA, Cawthon RM, Sandler DP, Chen H. Multivitamin use and telomere length in women. Am J Clin Nutr 2009;89:1857-63.

49 Farzaneh-Far R, Lin J, Epel ES, Harris WS, Blackburn EH, Whooley MA. Association of marine omega-3 fatty acid levels with telomeric aging in patients with coronary heart disease. JAMA 2010;303:250-7.

50 Cassidy A, De Vivo I, Liu Y, Han J, Prescott J, Hunter DJ, et al. Associations between diet, lifestyle factors, and telomere length in women. Am J Clin Nutr 2010;91:1273-80.
51 Trichopoulou A, Kouris-Blazos A, Vassilakou T, Gnardellis C, Polychronopoulos E, Venizelos M, et al. Diet and survival of elderly Greeks: a link to the past. Am J Clin Nutr 1995;61 (6 suppl):1346-50S

52 Scarmeas N, Stern Y, Mayeux R, Luchsinger JA. Mediterranean diet, Alzheimer disease, and vascular mediation. Arch Neurol 2006;63:1709-17.

53 Martinez-Gonzalez MA, de la Fuente-Arrillaga C, Nunez-Cordoba JM, Basterra-Gortari FJ, Beunza JJ, Vazquez Z, et al. Adherence to Mediterranean diet and risk of developing diabetes: prospective cohort study. BMJ 2008:336:1348-51.

54 Benetou V, Trichopoulou A, Orfanos P, Naska A, Lagiou P, Boffetta P, et al. Conformity to traditional Mediterranean diet and cancer incidence: the Greek EPIC cohort. Br J Cancer 2008;99:191-5.

55 Sofi F, Cesari F, Abbate R, Gensini GF, Casini A. Adherence to Mediterranean diet and health status: meta-analysis. BMJ 2008;337:a1344.

56 Trichopoulou A, Bamia C, Trichopoulos D. Anatomy of health effects of Mediterranean diet: Greek EPIC prospective cohort study. BMJ 2009;338:b2337.

57 Von Zglinicki T. Role of oxidative stress in telomere length regulation and replicative senescence. Ann N Y Acad Sci 2000;908:99-110.

58 Henle ES, Han Z, Tang N, Rai P, Luo Y, Linn S. Sequence-specific DNA cleavage by Fe2+-mediated fenton reactions has possible biological implications. J Biol Chem 1999;274:962-71.

59 Vallabhaneni $\mathrm{H}, \mathrm{O}^{\prime}$ Callaghan N, Sidorova J, Liu Y. Defective repair of oxidative base lesions by the DNA glycosylase Nth1 associates with multiple telomere defects. PLOS Genet 2013;9:e1003639.

60 Von Zglinicki T, Petrie J, Kirkwood TB. Telomere-driven replicative senescence is a stress response. Nat Biotechnol 2003;21:229-30.

61 Von Zglinicki T, Pilger R, Sitte N. Accumulation of single-strand breaks is the major cause of telomere shortening in human fibroblasts. Free Radic Biol Med 2000;28:64-74.

62 Von Zglinicki T, Saretzki G, Docke W, Lotze C. Mild hyperoxia shortens telomeres and inhibits proliferation of fibroblasts: a model for senescence? Exp Cell Res 1995;220:186-93.

63 Jacobs DR Jr, Gross MD, Tapsell LC. Food synergy: an operational concept for understanding nutrition. Am J Clin Nutr 2009;89:1543-8S.

64 Manson JE, Colditz GA, Stampfer MJ, Willett WC, Krolewski AS, Rosner B, et al. A prospective study of maturity-onset diabetes mellitus and risk of coronary heart disease and stroke in women. Arch Intern Med 1991;151:1141-7.

65 Ascherio A, Rimm EB, Giovannucci EL, Colditz GA, Rosner B, Willett WC, et al. A prospective study of nutritional factors and hypertension among US men. Circulation 1992;86:1475-84

66 Willett W, Stampfer MJ, Bain C, Lipnick R, Speizer FE, Rosner B, et al. Cigarette smoking, relative weight, and menopause. Am J Epidemiol 1983;117:651-8.

67 Zhu H, Wang X, Gutin B, Davis CL, Keeton D, Thomas J, et al. Leukocyte telomere length in healthy Caucasian and African-American adolescents: relationships with race, sex, adiposity, adipokines, and physical activity. J Pediatr 2011;158:215-20.

68 Hunt SC, Chen W, Gardner JP, Kimura M, Srinivasan SR, Eckfeldt JH, et al. Leukocyte telomeres are longer in African Americans than in whites: the National Heart Lung, and Blood Institute Family Heart Study and the Bogalusa Heart Study. Aging Coll2008:7:451-8.

69 Diez Roux AV, Ranjit N, Jenny NS, Shea S, Cushman M, Fitzpatrick A, et al. Race/ethnicity and telomere length in the Multi-Ethnic Study of Atherosclerosis. Aging Cell 2009;8:251-7.

\section{Accepted: 23 October 2014}

\section{Cite this as: BMJ 2014;349:g6674}

This is an Open Access article distributed in accordance with the Creative Commons Attribution Non Commercial (CC BY-NC 4.0) license, which permits others to distribute, remix, adapt, build upon this work non-commercially, and license their derivative works on different terms, provided the original work is properly cited and the use is non-commercial. See: http://creativecommons.org/licenses/by-nc/4.0/. 


\section{Tables}

Table 1| Age standardized characteristics of study population at blood draw, by quarters of leukocyte telomere length $\mathrm{z}$ score ( $\mathrm{n}=4676)$. Values are mean (SD)

\begin{tabular}{|c|c|c|c|c|c|}
\hline Baseline characteristics & Quarters of & leukocyte te & telomere lens & gth z score & $P$ for trend \\
\hline Age at blood draw ${ }^{*}$, years & $59.6(6.3)$ & $59.2(6.6)$ & $58.6(6.6)$ & $57.7(6.8)$ & $<0.001$ \\
\hline Body mass index at blood draw, $\mathrm{kg} / \mathrm{m}^{2}$ & $25.5(4.7)$ & $25.2(4.4)$ & $25.0(4.5)$ & $25.3(4.3)$ & 0.13 \\
\hline Pack years $\dagger$ & $23.9(20.8)$ & $22.8(18.8)$ & $23.5(20.4)$ & $22.9(18.9)$ & 0.024 \\
\hline Physical activity, metabolic equivalent hours of activity/week & $16.4(24.4)$ & $16.7(21.5)$ & $16.4(19.5)$ & $16.6(18.8)$ & 0.87 \\
\hline Total energy, kcal & $1790(508)$ & $1757(485)$ & $1743(487)$ & $1768(494)$ & 0.72 \\
\hline Vegetables, servings/day & $3.1(1.8)$ & $3.1(1.6)$ & $3.1(1.7)$ & $3.2(1.7)$ & 0.51 \\
\hline Fruits, servings/day & $2.4(1.3)$ & $2.4(1.3)$ & $2.4(1.5)$ & $2.5(1.4)$ & 0.81 \\
\hline Whole grains, servings/day & $1.5(1.3)$ & $1.5(1.2)$ & $1.5(1.2)$ & $1.5(1.3)$ & 0.77 \\
\hline Fish, servings/day & $0.4(0.4)$ & $0.3(0.3)$ & $0.3(0.3)$ & $0.4(0.3)$ & 0.68 \\
\hline Meats, servings/day & $0.8(0.5)$ & $0.7(0.5)$ & $0.7(0.5)$ & $0.8(0.5)$ & 0.54 \\
\hline Legumes, servings/day & $0.4(0.3)$ & $0.4(0.3)$ & $0.4(0.3)$ & $0.4(0.4)$ & 0.72 \\
\hline Nuts, servings/day & $0.4(0.6)$ & $0.4(0.5)$ & $0.3(0.5)$ & $0.4(0.6)$ & 0.91 \\
\hline Alcohol, g/day & $5.5(9.8)$ & $5.7(9.9)$ & $5.3(10.1)$ & $5.5(9.2)$ & 0.90 \\
\hline Total fat, g/day & $62.5(22.5)$ & $61.4(23.2)$ & $60.3(21.4)$ & $61.4(22.7)$ & 0.76 \\
\hline Total saturated fat, g/day & $21.0(8.0)$ & $20.7(8.6)$ & $20.3(8.0)$ & $20.5(8.1)$ & 0.95 \\
\hline Total monounsaturated fat, $\mathrm{g} / \mathrm{d}$ & $24.0(9.2)$ & $23.6(9.4)$ & $23.2(8.7)$ & $23.6(9.3)$ & 0.78 \\
\hline
\end{tabular}

*Values for age at blood draw are not age adjusted.

†Among ever smokers. 
Table 2| Age standardized characteristics of study population at blood draw, by groups of Alternate Mediterranean Diet score ( $\mathrm{n}=4676)$. Values are mean (SD)

\begin{tabular}{|c|c|c|c|c|c|c|}
\hline \multirow{2}{*}{$\begin{array}{l}\text { Baseline characteristics } \\
\text { Age at blood draw }{ }^{*} \text { years }\end{array}$} & \multicolumn{5}{|c|}{ Alternate Mediterranean Diet score groups } & \multirow{2}{*}{$\begin{array}{l}P \text { for trend } \\
<0.001\end{array}$} \\
\hline & $57.5(7.0)$ & $58.4(6.8)$ & $58.7(6.5)$ & $59.2(6.5)$ & $59.6(6.2)$ & \\
\hline Body mass index at blood draw, $\mathrm{kg} / \mathrm{m}^{2}$ & $25.6(4.5)$ & $25.2(4.2)$ & $25.3(4.7)$ & $25.2(4.3)$ & $25.0(4.5)$ & 0.010 \\
\hline Pack years $\dagger$ & $27.6(21.6)$ & $24.1(20.0)$ & $23.8(19.3)$ & $22.2(19.1)$ & $20.2(18.5)$ & $<0.001$ \\
\hline Physical activity, metabolic equivalent hours of activity/week & $13.2(18.6)$ & $14.0(17.9)$ & $16.2(27.0)$ & $17.9(20.0)$ & $20.1(21.2)$ & $<0.001$ \\
\hline Total energy, kcal & $1534(432)$ & $1630(459)$ & $1736(468)$ & $1847(480)$ & $1984(494)$ & $<0.001$ \\
\hline Vegetables, servings/day & $1.9(0.9)$ & $2.4(1.3)$ & $3.0(1.4)$ & $3.5(1.5)$ & $4.3(1.8)$ & $<0.001$ \\
\hline Fruits, servings/day & $1.5(0.9)$ & $1.9(1.1)$ & $2.4(1.4)$ & $2.7(1.3)$ & $3.2(1.4)$ & $<0.001$ \\
\hline Whole grains, servings/day & $0.8(0.9)$ & $1.2(1.1)$ & $1.4(1.2)$ & $1.7(1.2)$ & $2.1(1.3)$ & $<0.001$ \\
\hline Fish, servings/day & $0.2(0.1)$ & $0.2(0.2)$ & $0.3(0.2)$ & $0.4(0.4)$ & $0.5(0.3)$ & $<0.001$ \\
\hline Meats, servings/day & $0.9(0.5)$ & $0.8(0.5)$ & $0.8(0.5)$ & $0.7(0.5)$ & $0.6(0.5)$ & $<0.001$ \\
\hline Legumes, servings/day & $0.2(0.2)$ & $0.3(0.2)$ & $0.4(0.3)$ & $0.4(0.3)$ & $0.6(0.3)$ & $<0.001$ \\
\hline Nuts, servings/day & $0.2(0.5)$ & $0.3(0.5)$ & $0.3(0.5)$ & $0.4(0.5)$ & $0.5(0.6)$ & $<0.001$ \\
\hline Alcohol, g/day & $5.1(11.0)$ & $5.5(9.9)$ & $5.5(10.4)$ & $5.5(10.1)$ & $5.9(8.2)$ & 0.070 \\
\hline Total fat, g/day & $57.8(22.1)$ & $59.0(22.4)$ & $60.7(21.7)$ & $63.1(23.2)$ & $64.8(22.6)$ & $<0.001$ \\
\hline Total saturated fat, g/day & $20.9(8.7)$ & $20.5(8.4)$ & $20.7(8.2)$ & $20.7(8.2)$ & $20.4(7.9)$ & 0.084 \\
\hline Total monounsaturated fat, g/day & $22.1(8.8)$ & $22.7(9.2)$ & $23.2(8.7)$ & $24.2(9.5)$ & $25.1(9.3)$ & $<0.001$ \\
\hline
\end{tabular}


Table 3| Estimated least squares mean telomere length $\mathbf{z}$ scores (and standard errors) by Mediterranean diet score categories (Alternate Mediterranean Diet score) in Nurses' Health Study ( $n=4676)$

\begin{tabular}{lcccccc}
\multicolumn{7}{c}{ Alternate Mediterranean Diet score } \\
\cline { 2 - 6 } Analysis & $\mathbf{5}(\mathbf{n = 8 9 1 )}$ & $\mathbf{3}(\mathbf{n = 7 9 5 )}$ & $\mathbf{4}(\mathbf{n = 9 0 9 )}$ & $\mathbf{5}(\mathbf{n = 8 8 0})$ & $\mathbf{2 6}(\mathbf{n = 1 2 0 1 )}$ & P for trend \\
Age adjusted & $-0.028(0.033)$ & $-0.039(0.035)$ & $-0.011(0.033)$ & $0.029(0.033)$ & $0.054(0.029)$ & 0.016 \\
\hline Multivariable adjusted $^{*}$ & $-0.038(0.035)$ & $-0.049(0.036)$ & $-0.010(0.033)$ & $0.039(0.034)$ & $0.072(0.030)$ & 0.004 \\
\hline
\end{tabular}

*Adjusted for age, body mass index, pack years of smoking, physical activity, and total caloric intake. 
Table 4 | Estimated least squares mean of telomere length $\mathbf{z}$ scores by quarters of individual Alternate Mediterranean Diet components in Nurses' Health Study ( $n=4676)$

\begin{tabular}{|c|c|c|c|c|}
\hline Component & No & Least squares means (SE) & $95 \% \mathrm{Cl}$ & $P$ for trend \\
\hline Vegetables (servings/day): & & & & 0.37 \\
\hline Q1 & 1165 & $-0.005(0.032)$ & -0.067 to 0.057 & \\
\hline Q2 & 1167 & $-0.039(0.030)$ & -0.097 to 0.018 & \\
\hline Q3 & 1168 & $0.032(0.029)$ & -0.025 to 0.090 & \\
\hline Q4 & 1176 & $0.045(0.032)$ & -0.017 to 0.108 & \\
\hline Fruit (servings/day): & & & & 0.41 \\
\hline Q1 & 1180 & $-0.004(0.031)$ & -0.066 to 0.057 & \\
\hline Q2 & 1167 & $0.0007(0.030)$ & -0.057 to 0.059 & \\
\hline Q3 & 1168 & $0.021(0.030)$ & -0.036 to 0.079 & \\
\hline Q4 & 1161 & $0.015(0.032)$ & -0.047 to 0.078 & \\
\hline Whole grains (servings/day): & & & & 0.35 \\
\hline Q1 & 1160 & $-0.047(0.031)$ & -0.107 to 0.014 & \\
\hline Q2 & 1204 & $0.012(0.029)$ & -0.045 to 0.069 & \\
\hline Q3 & 1177 & $0.058(0.029)$ & 0.0003 to 0.115 & \\
\hline Q4 & 1135 & $0.008(0.031)$ & -0.053 to 0.070 & \\
\hline Fish (servings/day): & & & & 0.52 \\
\hline Q1 & 1257 & $-0.013(0.029)$ & -0.070 to 0.044 & \\
\hline Q2 & 772 & $0.004(0.036)$ & -0.067 to 0.075 & \\
\hline Q3 & 1470 & $0.012(0.026)$ & -0.040 to 0.064 & \\
\hline Q4 & 1177 & $0.029(0.031)$ & -0.031 to 0.089 & \\
\hline Meat (servings/day): & & & & 0.15 \\
\hline Q1 & 1173 & $0.018(0.032)$ & -0.045 to 0.082 & \\
\hline Q2 & 1170 & $-0.005(0.030)$ & -0.063 to 0.053 & \\
\hline Q3 & 1179 & $-0.028(0.029)$ & -0.086 to 0.030 & \\
\hline Q4 & 1154 & $0.049(0.033)$ & -0.016 to 0.113 & \\
\hline Legumes (servings/day): & & & & 0.33 \\
\hline Q1 & 821 & $0.002(0.036)$ & -0.068 to 0.073 & \\
\hline Q2 & 1546 & $0.009(0.026)$ & -0.041 to 0.060 & \\
\hline Q3 & 1106 & $-0.011(0.030)$ & -0.071 to 0.048 & \\
\hline Q4 & 1203 & $0.029(0.031)$ & -0.031 to 0.089 & \\
\hline Nuts (servings/day): & & & & 0.24 \\
\hline Q1 & 1561 & $-0.034(0.026)$ & -0.086 to 0.018 & \\
\hline Q2 & 797 & $-0.006(0.036)$ & -0.076 to 0.063 & \\
\hline Q3 & 1183 & $0.014(0.029)$ & -0.043 to 0.071 & \\
\hline Q4 & 1135 & $0.070(0.032)$ & 0.008 to 0.133 & \\
\hline Alcohol (g/day): & & & & 0.53 \\
\hline Q1 & 1804 & $0.008(0.024)$ & -0.039 to 0.055 & \\
\hline Q2 & 497 & $-0.012(0.045)$ & -0.100 to 0.076 & \\
\hline Q3 & 1206 & $-0.018(0.029)$ & -0.075 to 0.039 & \\
\hline Q4 & 1169 & $0.044(0.030)$ & -0.015 to 0.104 & \\
\hline Monounsaturated:saturated fatty acid ratio: & & & & 0.81 \\
\hline Q1 & 1141 & $0.007(0.030)$ & -0.052 to 0.066 & \\
\hline Q2 & 1139 & $0.013(0.030)$ & -0.045 to 0.072 & \\
\hline Q3 & 1241 & $0.032(0.029)$ & -0.024 to 0.088 & \\
\hline Q4 & 1155 & $-0.021(0.031)$ & -0.082 to 0.039 & \\
\hline
\end{tabular}

*Adjusted for age, body mass index, pack years of smoking, physical activity, total caloric intake, and intakes of other components of Alternate Mediterranean Diet score. 


\section{Figure}
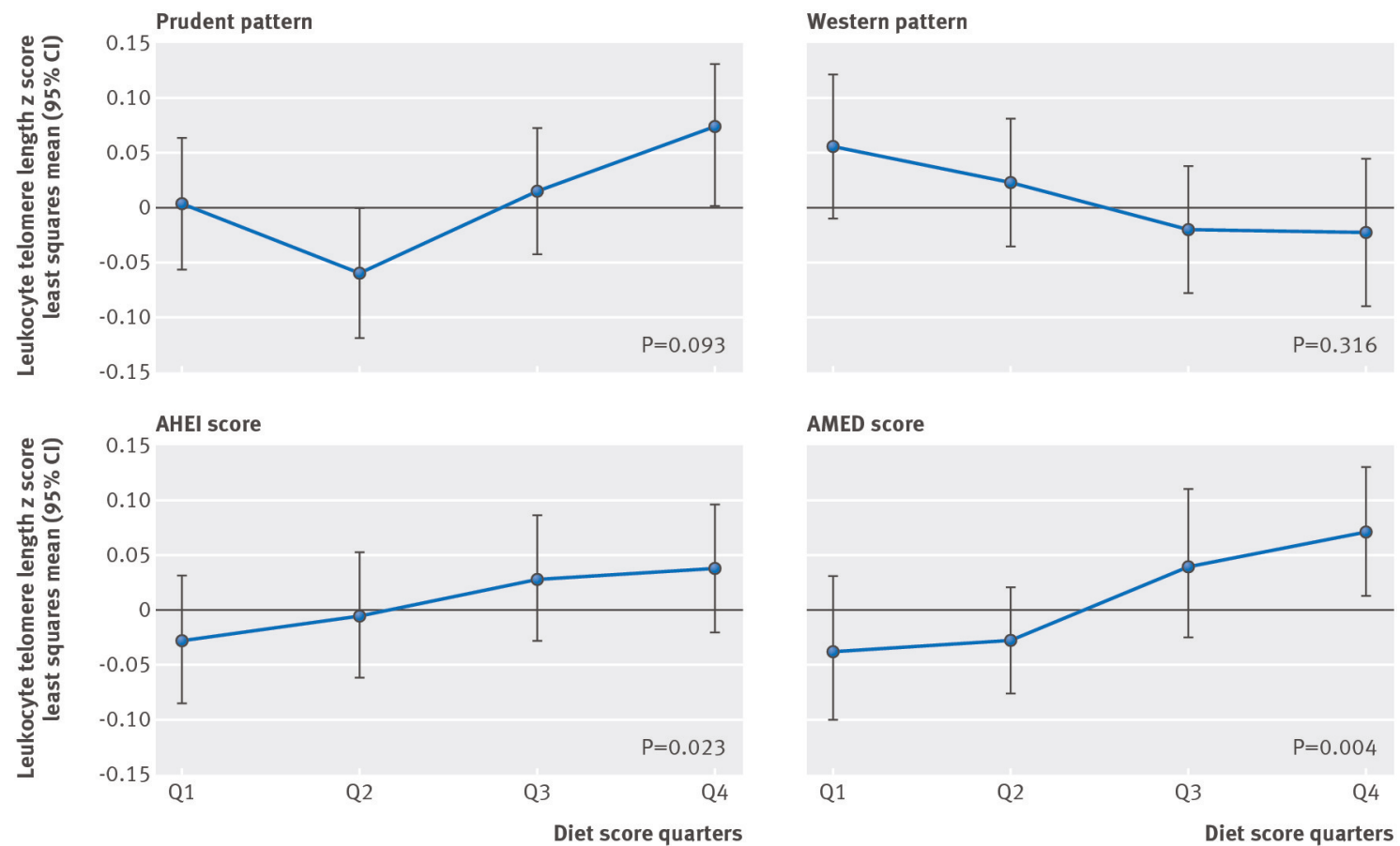

Multivariable adjusted least square means of leukocyte telomere length z scores (and their corresponding confidence intervals) by diet score quarters. All dietary patters are represented: prudent pattern, Western pattern, Alternative Healthy Eating Index (AHEI) score, and Alternate Mediterranean Diet (AMED) score 